\title{
THE DETECTION OF URINAL NEOPTERIN CONCENTRATION INCREASES THE EFFICIENCY OF CERVICAL SMEAR IN THE DIAGNOSIS OF CERVICAL CANCER
}

\author{
Merih Bayram $^{1}$, Hakan Boyunaga ${ }^{2}$, Kemal Diribas $^{3}$, Guler Ozer ${ }^{1}$, Emin Ozgur Akgul', M Kemal Erbil $^{4}$
}

Kirikkale University, Faculty of Medicine, Kirikkale, Turkey: Department of Obstetrics and Gynecology ${ }^{1}$, Department of Biochemistry $^{2}$; Kalecik State Hospital, Kirikkale, Turkey: Department of Gynecology and Obstetrics ${ }^{3}$; Academy of Gulhane Ministry Medical, Ankara, Turkey: Department of Biochemistry and Clinic Biochemistry ${ }^{4}$

Summary: Objective: To investigate the importance of urinal neopterin detection carried out together with cervical smear test, in the diagnosis of cervical cancer. Methods: In this study, urine samples were collected from randomly selected vulvovaginitis' women who attended hospital and an independent control group. The participants were classified into two representative sample groups and a control group; $1^{\text {st }}$ Group: 35 women with vulvovaginitis, whose ages varied fro 21 to 42 and who had no viral infections, and chronic inflammatory diseases and no smoking habit, but had complaints of vaginal discharge. $2^{\text {nd }}$ Group: 25 women aged between 38-52 with no smoking habit, who applied to hospital with complaints of vaginal discharge, and cervical cancer was diagnosed for them as the result of biopsy, but no associated treatment of cancer had been carried out yet. $3^{\text {rd }}$ Group: A control group with 30 women who aged between 20 and 28 , with no smoking habit, and who had not taken part in sexual activities yet. They had no complaints from any type of tumors, and viral infections or chronic inflammatory diseases. Urinalysis was carried out for each group member's urine sample in order to measure the level of neopterin. Neopterin was estimated by HPLC. Some statistical analyses were done by SPSS Windows 10.0 and were analyzed by Oneway Annova test. $(p=0.000)$ Meaningful differences between the groups were determined by Post Hoc Tukey Test. Results: The mathematical results of neopterin levels for the groups revealed that the level of Group 1 was significantly higher than the level of Group $3(\mathrm{p}=0.0001)$. When the levels of Group 1 and 2 were compared with each other, a significant difference was determined $(p=0.004)$. Also, the difference in the levels of Group 2 and 3 was found to be significant ( $p=0.0001$ ). Conclusions: If the results of this study were not confounded by another factor, then we can deduce that an increment in the level of neopterin may be considered as a risk factor that should warrant further investigation of cervical cancer. Then, the detection of urinal neopterin level as a noninvasive test done together with cervical smear can increase the sensitivity of smear test.

Key words: Cervical cancer; Neopterin; Efficiency; Risk factor

\section{Introduction}

Neopterin is a substance having low molecular weight (253.22), which is excreted by the kidneys. Neopterin was determined in bee larva in 1963 for the first time (20). The first determination in humans was found in urine with a study carried out in 1967 (21). High neopterin leap was noticed in the urine of patients with viral infections and malignities in 1979 (24). Since neopterin generally remains stable in the body fluids, it is not usually difficult to measure neopterin levels by routine laboratory tests. Neopterin concentration can be used to determine the activation of cellular immune response. Some pathologies in which urinal neopterin increase could be observed, are viral infections (acute hepatitis A and B, mononucleosis, cytomegalovirus, measles, HIV) $(6,7,9,14)$ and infections with intercellular bacteria and parasites (tuberculosis, leprosy, melioidosis, malaria and schistosomiasis) $(2,5,16,23,27)$, autoimmune diseases (rheumatoid arthritis, systemic lupus erythematosus, dermatomyositis, multiple sclerosis) $(4,11,17,22)$ allograft rejections (10), malignant diseases. An increment in urinal neopterin was determined among gynecological cancers, particularly in ovarian cancer $(13,19)$. At tumoral stages, some significant relations of neopterin level ware detected. In cervical $\mathrm{Ca}$, lower neopterin level has been observed than the one in ovarian cancer (50-60\%) (15).

Cervico-vaginal cytology (smear) is exfoliative cytological technique (1). However cytology is not a certain evidence to the existing disease, but rather a guide to the other methods such as colposcopy and histopathology. In other 
words, it is a kind of medical consultation. The function of the cytology is to schedule the clinical and laboratory operations required for the patient. The advantages of smear are easiness of sampling and inspection, repeatability and diagnosis with high correctness. All these advantages make the smear test be used as a screening method in the world widely. Papanicolau showed that cervico-vaginal cytology can be used in the diagnosis of cervical cancer (12).

This prospective clinical study was performed to investigate the importance of urinal neopterin detection done together with cervical smear test, in the diagnosis of cervical cancer.

\section{Material and methods}

\section{Patients}

The study was based on 90 female patients allocated into three groups.

$1^{\text {st }}$ Group: 35 women who suffered from vulvovaginitis, and whose ages varied from 21 to 42 . They attended to the Gynecology and Obsterics Polyclinic of the Faculty of Medicine-Kirikkale University and Kalecik State Hospital with a complaint of vaginal discharge. They had no viral infections and any other chronic inflammatory diseases and they were none-smokers.

$2^{\text {nd }}$ Group: 25 women aged between 38 and 52, who applied to the clinic with complaints of vaginal discharge, and the cervical cancer was diagnosed for them as the result of biopsy, but no associated treatment of cancer had been carried out yet. They were also non-smokers and they didn't have any chronic inflammatory diseases, and viral infections. Standardization of the study, only the cervical cancer patients with stage I according to FIGO 1998 were included to this group.

$3^{\text {rd }}$ Group was formed as a control group. For this group, 30 healthy women whose ages varied from 20 to 28 were randomly selected. They were non- smokers, and who had not taken part in sexual activities yet. They had no complaints from any type of tumors, and viral infections or chronic inflammatory diseases.

\section{Pathological procedure}

Smears are taken from the patients with cytobrush at optimal conditions. They were examined carefully by one cytopathologist and the results were obtained by Bethesda system. Biopsies were done from multiple focuses under colposcopy by using punch (Kevorkian) biopsy pens and the materials were sent to a pathologist in \%10 formalin solution.

\section{Laboratory examination}

Urine samples were taken from all group members to measure the levels of neopterin. From all members, urine samples were taken as their first excretion early in the morning when they started attending hospital for routine tests. Because of the light sensitivity of neopterin, the spe- cimens were protected from direct sunlight during transport and storage. All the samples were kept in a light-proof containers at $-20 \mathrm{C}$ until the time that they would be analyzed. The measurements were taken with the methods described by Fuchs ${ }^{3}$. A - Hewlett Packard-1050 USA- was employed as the High Performance Liquid Chromatography (HPLC) instrument, and as the analytic column, an (Allsphere ODS-2 Reverse-Phase column Alltech, Deerfield, IL, USA) and as the guard column a (Spherisorb ODS-2 Cartridge Alltech, Deerfield, IL, USA) were employed for the analyses at GATA Biochemistry and Clinical Biochemistry Laboratories. The results were calculated as neopterin/creatinine content for each sample and reported in terms of $\mathrm{mol} / \mathrm{mol}$.

\section{Statistical analysis}

Interpretation of urinary neopterin/creatinine ratios were done under SPSS Windows 10.0. The neopterin levels of the two sample groups (Group 1 and 2) and the control group (Group 3) were assessed by Oneway Annova test. $(p=0.000)$ The differences of between the group results were determined by the Post Hoc Tukey Test.

\section{Results}

Urinary neopterin levels of three test groups are tabulated below in Table 1, and the test results illustrated in Fig. 1.

Tab. 1: Groups and neopterin levels.

\begin{tabular}{|c|c|c|}
\hline Groups & $\begin{array}{c}\text { Neopterin } \mu \mathrm{mol} \\
\text { neopt/mol cre } \\
\text { Median (min - max })\end{array}$ & $\begin{array}{c}\text { Standard } \\
\text { deviation } \\
(\mathrm{SD})\end{array}$ \\
\hline 1. group $(\mathrm{n}=35)$ & $198.4(87.3-314.2)$ & 56.6 \\
\hline 2. group $(\mathrm{n}=25)$ & $559.6(134.7-1407.0)$ & 340.3 \\
\hline 3. group $(\mathrm{n}=30)$ & $94.9(54.0-147.3)$ & 25.1 \\
\hline
\end{tabular}

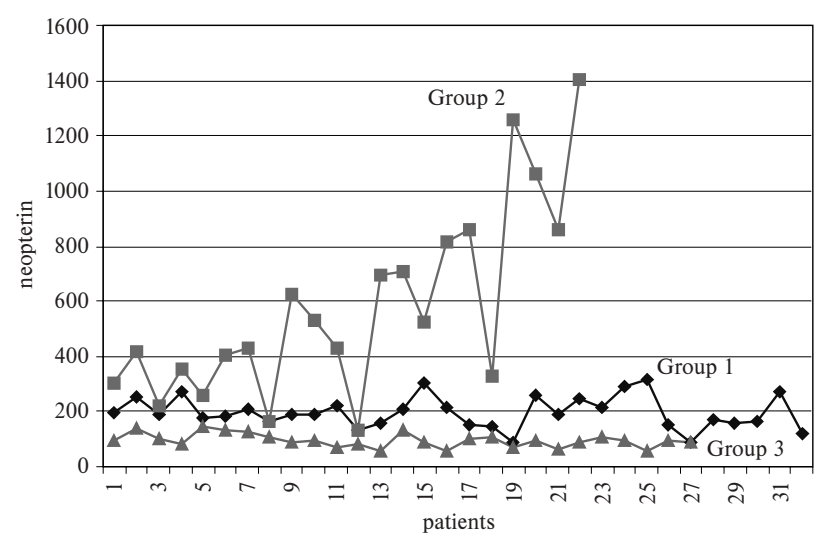

Fig. 1: Groups and neopterin levels.

\section{Pathological results}

$1^{\text {st }}$ Group: The smear results of 35 patients with vulvovaginitis revealed inflammation. The biopsy results of all the members of this group were normal. 
$2^{\text {nd }}$ Group: The smear results of 25 patients with cervical cancer revealed 3 adenocarcinoma, 5 HighSIL, 3 LowSIL, and 14 inflammatory changes.

The biopsy results of all the members of this group revealed adenocarcinoma.

$3^{\text {rd }}$ Group: The results of smear and biopsy seemed to be normal.

The differences by the ages in the groups were detected by Oneway Anova Test $(\mathrm{p}=0.000)$. Meaningful differences between the groups were determined by Post Hoc Tukey Test.

\section{Discussion}

The increasing amount of urinary neopterin in malignant diseases and viral infections could be attributed to the facts that the cellular growth and cellular proliferation occur with the formation of neopterin, thus causing the leap in its concentration. So that no change in neopterin concentration can be observed in benign tumors. The study in 1981 has shown that neopterin formation occurs with the activation of cellular immune system (24).

Since neopterin is produced in cells of the immune system, but not by tumor cells, neopterin is not a tumor marker per se. T-cell activation, which is probably induced by malignantly transformed cells, leads to cytokine production, macrophage activation and ultimately, neopterin release. The sensitivity of the neopterin test is greatly dependent on the localization of the malignant disease (18).

The strength of neopterin testing does not lie in tumor screening, but in determination of the prognosis and in monitoring of therapy results in patients with malignant diseases $(15,25)$. Neopterin testing therefore seems to suggest itself as a supplementary monitoring method in tumor follow-up, in which case an increase in the neopterin concentration indicates the necessity to initiate further diagnostic measures. The neopterin concentration can also be used as an additional indicator for differentiation between benign and malignant tumors.

As long as renal functions is more or less normal, serum and urinary neopterin measurements are comparably sensitive for detection of disease developments associated with the activation of cellular immune system. The neopterin concentration in the urine is assessed according to the creatinin levels. In some previous studies, urinal neopterin concentration was found with a mean level of $128 \pm 33 \mu \mathrm{mol}$ neopterin/mol creatinin among women aged between 19 and 25 , and $124 \pm 33 \mu \mathrm{mol}$ neopterin/mol creatinin among women aged between 26 and $35,140 \pm 39 \mu \mathrm{mol}$ neopterin/mol creatinin among women aged between 36 and 45, 147 $\pm 32 \mu \mathrm{mol}$ neopterin/mol creatinin among women aged between 46 and 55, $156 \pm 35 \mu \mathrm{mol}$ neopterin $/ \mathrm{mol}$ creatinin among women aged between 56 and 65 , and finally $141 \pm 40 \mu \mathrm{mol}$ neopterin/mol creatinin among the ones aged more than 65 (26).

In this study, the differences in the levels of neopterin concentration classified according to the ages of women seemed to be in accordance with the above findings. Further- more, the results of Group 2 showed that in spite of the influence of age, the tumoral effect also played an important role in the level of neopterin concentration.

The incidence of increased neopterin in cervical cancer (Ca) is $50-60 \%(15)$. In the diagnosis of cervical $\mathrm{Ca}$, the sensitivity of smear was found to be $60-80 \%$ and pseudo-negativity was notified as to be $20-40 \%$ (8). In the diagnosis of cervical $\mathrm{Ca}$, the algoritm are smear, colposcopy and biopsy. In this algorithm, the sensitivity of smear is $60-80 \%$ (8).

In our study, cervical cancer case was observed with the incidence of $27.7 \%$. In Group 2, the malignancy was diagnosed with a rate of $32 \%$ by cervical smear test. In literature survey, this ratio seems to be $60-80 \%$. When we compared the levels of neopterin concentration of Group 2 with the normal values (of the Control Group) the levels seemed to be high in $88 \%$ of the group findings. This increment was also statistically meaningful among the members of Group 1, the neopterin concentrations were high with the rate of 60 . When the results of Group 1 and Group 2 were compared with each other, there seemed to be a statistically significant relationship among them.

In this study we have not determined the sensitivity and specificity of urinal neopterin, because it required a large number of patients to be detected.

If the results of this study were not confounded by another factor, then we can deduce that increment in the level of neopterin concentration may be considered as a risk factor that should warrant further investigation of cervical cancer. Then, the detection of urinal neopterin level- as a noninvasive test- together with cervical smear can increase the efficiency of smear test.

\section{References}

1. Bozkurt S. Jinekolojik onkolojide servikovaginal sitoloji. Jinekolojik Onkoloji, ed. Atasü T,Aydinli K.Logos Yay.Istanbul-Turkey,1999:190-220.

2. Brown AE, Dance DA, Chaowagul W, Webster HK, White NJ. Activation of cellular immune responses in melioidosis patients as assessed by urinary neopterin. Trans R Soc Trop Med Hyg 1990;84(4):583-4.

3. Brown GM. The biosynthesis of pteridines. Adv Enzymol. 1971;35:5-77.

4. Fredrikson S, Link H, Eneroth P. CSF neopterin as marker of disease activity in multiple sclerosis. Acta Neurol Scand 1987;75(5):352-5.

5. Fuchs D, Hausen A, Kofler M, Kosanowski H, Reibnegger G, Wachter H. Neopterin as an index of immune response in patients with tuberculosis. Lung $1984 ; 162 ; 337-46$

6. Fuchs D, Hausen A, Reibnegger G, Werner ER, Dierich MP, Wachter H. Neopterin as a marker for activated cell-mediated immunity:Application in HIV infection. Immunol Today 1989;9:150-5.

7. Griffin DE, Ward BJ, Jauregui E, Johnson RT, Vaisberg A. Immune activation during measles:Interferon- gamma and neopterin in plasma and cerebrospinal fluid in complicated and uncomplicated disease. J Infect Dis 1990;161(3): 449-53.

8. Hurt WG, Silverberg SG, Frable WJ, Belgrad R, Crooks LD. Adenocarcinoma of cervix: histopathologic and clinical features. Am J Obstet Gynecol 1977; 129(3):304-15

9. Kern P, Rokos H, Dietrich M. Raised serum levels and imbalances of T-lymphocyte subsets in viral diseases,acquired immune deficiency and related lymphadenopathy syndromes. Biomed Pharmacother 1984;38(8):407-11.

10. Mayersbach P, Augustin R, Schennach H et al. Commercial enzyme-linked immunosorbent assay for neopterin detection in blood donations compared with RIA and HPLC. Clin Chem 1994;40(2):265-6.

11. Nassonov EL, Samsonov MY, Tilz GP et al. Serum concentrations of neopterin, soluble interleukin-2 receptor and soluble tumor necrosis factor receptor in Wegener's granulomatosis. J Rheumatol 1997;24(4):666-70. 
12. Papanicolau GN. New cancer diagnosis. "Proceedings of the Third Race Betterment Conference". New York,1928.

13. Park IS, Lee YS, Kim JC, Hwang SG. Serum neopterin levels in ovarian tumors. Int J Gynaecol Obstet 1995;51(3):229-34.

14. Reibnegger G, Auhuber I, Fuchs Det al. Urinary neopterin levels in acute viral hepatitis.Hepatology 1988;8(4):771-4.

15. Reibnegger G, Bichler A, Dapunt $O$ et al. Neopterin as a prognostic indicator in patients with carcinoma of the uterine cervix. Cancer Res 1986;46(2):950-5.

16. Reibnegger G, Boonpucknavig V, Fuchs D, Hausen A, Schmutzhard E, Wachter $\mathrm{H}$. Urinary neopterin is elevated in patients with malaria. Trans Roy Soc Trop Med Hyd 1984;78:545-6.

17. Reibnegger G, Egg D, Fuchs D et al. Urinary neopterin reflects clinical activity in patients with rheumatoid arthritis. Arthritis Rheum 1986;29(9):1063-70.

18. Reibnegger G, Fuchs D, Fuith LC et al. Neopterin as a marker for activated cellmediated immunity:Application in malignant disease. Cancer Detect Prevent 1991;15(6):483-90.

19. Reibnegger G, Hetzel H, Fuchs D et al. Clinical significance of neopterin for prognosis and follow-up in ovarian cancer. Cancer Res 1987;47(18):4977-81.

20. Rembold H, Buschmann L. Struktur und synthese des neopterins. Chem Ber 1963;96:1406-10.

21. Sakurai A, Goto M. Neopterin: isolation from human urine. J Biochem 1967; 61:142-5.

22. Samsonov MY, Tilz GP, Egorova O et al. Serum soluble markers of immune activation and disease activity in systemic lupus erythematosus. Lupus $1995 ; 4(1) ; 29-32$.
23. Schmutzhard E, Fuchs D, Haussen A, Reibnegger G, Wachter H. Is neopterina marker of cell mediated immune response-helpful in classifying leprosy? East Afr Med J 1986;63(9):577-80.

24. Wachter H, Hausen A, Graněmecká betamayr K. Erhöhte Ausscheidung von Neopterin im Harn von Patienten mit malignen Tumoren und mit Viruserkrankungen. Hoppe-Seyler's Z Physiol Chem 1979;360:1957-60.

25. Weiss G, Fuchs D, Hausen A et al. Neopterin modulated toxicity mediated by re active oxygen and chloride species. FEBS Lett 1993;321(1):89-92.

26. Werner ER, Bichler A, Daxenbichler G et al. Determination of neopterin in serum and urine. Clin Chem 1987;33(1):62-6.

27. Zwingenberger $\mathrm{K}$, Harms G, Feldmeier $\mathrm{H}$, Muller O, Steiner A, Bienzle U. Live involvement in human schistosomiasis mansoni.Regression of immunologica and biochemical disease markers after specific treatment. Acta Tropica 1988;45(3):263-75.

Submitted November 2003

Accepted February 2004.

Merih Bayram, M.D.,

Bilkent 1, D: 4 No: 9

Bilkent-Ankara 06530, Turkey.

e-mail: merbay@ttnet.net.tr 